\title{
BIOLOGICALLY ACTIVE COMPOUND STABILITY IN THE INDUSTRIAL POTATO PROCESSING BY-PRODUCTS
}

\author{
Igor Sepelevs $^{1 *}$, Ilva Nakurte ${ }^{2}$, Ruta Galoburda ${ }^{1}$ \\ 1* Department of Food Technology, Faculty of Food Technology, Latvia University of Life Sciences and Technologies, \\ Rigas iela 22, Jelgava, Latvia, e-mail: igor_shepelev@inbox.lv \\ ${ }^{2}$ Department of Physical Chemistry, Faculty of Chemistry, University of Latvia, Jelgavas iela 1, Riga, Latvia
}

\begin{abstract}
The biologically active compound extraction from potato peel by-products is an actual topic that is targeted not only on the new product development but also provides an important insight into industrial by-product recycling possibilities. As actual information on the extractable biologically valuable compound stability during the industrial potato peel by-products storage is scarce, the aim of present research had been to analyse phenolics and glycoalkaloids degradation tendencies in potato processing by-products (peels form different abrasion peeling lines), imitating the actual industrial storage conditions. In the present study, $\alpha$-solanine and $\alpha$-chaconine were the most stable among the analysed compounds. Chlorogenic acid concentration showed slower decrease rates in large and middle size peel pieces during the first days of storage, when compared to small size samples (possibly due to ongoing chlorogenic acid synthesis form phenylalanine). The peel material that does not contain whole cells (ground peel) is not recommended for extracting purposes due to the rapid phenolic compound oxidation and degradation. Alternatively, peel material that consists of large and middle size peels can be used for the extraction purposes during the first two days of peel storage under industrial storage conditions, without major decreases in the yield. Deeper studies on biologically active compound degradation dynamics are necessary to maximise the extraction yield of phenolics and glycoalkaloids from the industrial potato processing wastes.
\end{abstract}

Keywords: potato peel, by-product recycling, glycoalkaloids, phenolics.

\section{Introduction}

One of the most important crops for human consumption are potatoes (Solanum tuberosum L.), with an approx. $32 \mathrm{~kg}$ per capita worldwide. As a result, industrial potato production waste management is rising a concern European for the potato industry. On our road to the sustainable economy, an environmentally friendly solution should be found. A number of studies were conducted showing that potato peel, one of the major potato processing waste (Al-Weshahy, Rao, 2012), is a potential source for methane (Liang, McDonald, 2015), biofuel (Liang, McDonald, 2014), lactic acid (Liang et al., 2014), pullulan (Göksungur et al., 2011), and another valuable compound production (Matharu et al., 2016). For the food industry, biologically active compound extraction and further application in food production is one of the main recycling possibilities, and the number of researches have been evaluating possible processing methods (Al-Weshahy, Rao, 2012; $\quad$ Amado et al., 2014; Cardoso et al., 2013; $\quad$ Hossain et al., 2014; Luthria, 2012; Samarin et al., 2012; Wijngaard et al., 2012). Despite that, not much research had been conducted to understand the actual raw material (peel) storage time before the recycling/extraction process, to ensure maximal biologically active compound yield and minimal degradation rates.

Two types of potato by-products (peeling wastes) can be distinguished based on the peeling method: steam and abrasion peeling. Depending on parameters, steam peeling can result in almost $90 \%$ losses in the total glycoalkaloid content, and also reduces total phenolic compound content by $67 \%$ (Mäder et al., 2009). As those are main biologically active compounds that potato peel is known for (Schieber, Saldaña, 2009), abrasion peeling wastes are more suitable as a raw material for extraction purposes as it provides higher yields. Phenolics and glycoalkaloids are distributed unevenly between different parts of potato tuber, with most of them being located exactly in the peel (LopezCobo et al., 2014), which makes abrasion peeling wastes even more perspective source for extraction purposes than the whole tuber itself. It is also important to take in the consideration that content, composition, and distribution of biologically active compounds in potato tuber is highly dependent on the potato variety (Navarre et al., 2011).

Phenolic compounds (a secondary plant metabolites) form a heterogeneous class of organic compounds in plants, providing pigmentation and protection against various external factors (ultraviolet light, pathogenic microorganisms, another) (Williams, Grayer, 2004). In potato peels, they are represented mostly by an ester of caffeic and quinic acids - chlorogenic acid. And it can form up to $90 \%$ of all phenolics in potato tuber (Friedman, 1997; Im et al., 2008). Another important group of secondary metabolites in plants is glycoalkaloids. These compounds are toxic to viruses, microorganisms, insects, animals, and even to humans. In potatoes they are represented mostly by $\alpha$-solanine and $\alpha$-chaconine, both containing the same aglycone solanidine (Rayburn et al., 1994). Their content is influenced by many post-harvest factors and can vary greatly between tubers, depending on the potato variety itself, exposure to light and irradiation, presence of mechanical injuries, and another storage (Friedman, 2004).

As a result, due to its composition, the potato peel extract is known for exhibiting antioxidative and antiradical activities (Friedman et al., 2017). It was able to prevent lipid oxidation in oil-in-water emulsions and plant oils (Habeebullah et al., 2010), minced mackerel meat (Sabeena Farvin et al., 2012), and ground beef patties (Mansour, Khalil, 2000). In addition, it showed 
the ability to reduce the toxicity of cholesterol oxidation products (Hsieh et al., 2016) and to protect erythrocytes against oxidative damage (Singh, Rajini, 2008), and other health-positive effects.

To ensure the best quality and maximal yield of produced extracts from potato peel wastes on the industrial scale, it is important to ensure the quality of the raw material. The aim of the present study was to analyse biologically active compound degradation tendencies in potato processing wastes (peels) from the abrasion peeling lines, during the storage at ambient conditions.

\section{Materials and Methods}

Potato samples

As the present study is discussing biologically active compound degradation in order to determine the optimal storage conditions for industrial potato processing by-products, so they could be further recycled, a new potato (Solanum tuberosum L., cultivar 'Magdalena', pedigree 82-28.9/15876.41) genotype specially developed for industrial processing purposes had been used. Potato tubers were donated by the State Priekuli Plant Breeding Institute (currently Institute of Agricultural Resources and Economics, Latvia). Sample preparation, storage, and extract preparation were carried out in the Department of Food Technology, Latvia University of Life Sciences and Technologies, in Fall of 2015. LC-HRMS analysis was conducted in the same year in the Department of Chemistry, University of Latvia.

\section{Chemicals and reagents}

Agricultural origin ethanol $(96.6 \%)$ had been obtained from 'Stumbras' (Kaunas, Lithuania). All standards ( $\alpha$ solanine, $\alpha$-chaconine, chlorogenic acid), acetonitrile, and formic acid were purchased from Sigma-Aldrich (currently Merck KGaA, Darmstadt, Germany).

\section{Extract preparation}

The preliminary study on industrial potato processing by-products in Latvia (data is not shown) showed that three main potato peel types are available as wastes: large peel pieces (approx. $5 \mathrm{~cm}$ ), small peel pieces (approx. $5 \mathrm{~mm}$ ), and finely shredded peel. Based on the acquired data, similar three types of peel samples had been produced. They were stored in the open plastic container at ambient conditions for 6 days at room temperature $\left(21 \pm 2{ }^{\circ} \mathrm{C}\right)$, without additional aeration. Once a day, each sample type was collected, freeze-dried using Armfield FT33 (Ringwood, UK) with a final moisture content of ca. $5 \%$, ground in the laboratory scale mill Foss KN 195 Knifetec (Hillerod, Denmark), and were immediately used for the extraction purposes. The whole experiment was repeated in three consecutive batches. The remaining moisture content was determined gravimetrically at $105{ }^{\circ} \mathrm{C}$.

\section{Biologically active compound extraction}

$80 \%$ ethanol had been used as a solvent (Mane et al., 2015). In short, $2 \mathrm{~g}$ of prepared potato peel powder was dispersed in $20 \mathrm{~mL}$ of the solvent. Extractions were conducted under the ultrasound treatment using YJ 5120-1, Citizen Scale (Mumbai, India), for $15 \mathrm{~min}$ at $33 \pm 1{ }^{\circ} \mathrm{C}$. Supernatants were separated by a centrifuging, ELMI CM (Riga, Latvia), for $15 \mathrm{~min}$ at 2,500 $\times \mathrm{g}$. The extraction of the same sample had been repeated three times and acquired supernatants were combined and used for further analyses.

\section{Liquid chromatography and mass spectrometry}

Liquid chromatography - high-resolution mass spectrometry (LC-HRMS) had been performed on a Agilent 1290 Infinity UHPLC system, Agilent Technologies (Santa Clara, USA). Compound separations were performed on the Atlantis dC18 $3.5 \mu \mathrm{m}$ column $(2.1 \times 150 \mathrm{~mm})$, Waters (Dublin, Ireland). The elution solvents consisted of $0.1 \%$ formic acid solution (A) and acetonitrile (B). The flow rate was $0.3 \mathrm{~mL} \mathrm{~min}^{-}$ ${ }^{1}$, with the 22 min gradient. The program was as follows: $5 \% \mathrm{~A}$ in $2 \mathrm{~min}, 5-95 \% \mathrm{~A}$ in $10 \mathrm{~min}$, keep $95 \%$ of $\mathrm{A}$ for $5 \mathrm{~min}, 95-5 \% \mathrm{~A}$ in $2 \mathrm{~min}$, keep $5 \%$ of A for $3 \mathrm{~min}$. The HRMS had been performed on the Agilent $6230 \mathrm{TOF}$ LC/MS system, Agilent Technologies (Santa Clara, USA), using both positive and negative electrospray ionization. Applied parameters: drying gas flow $10.0 \mathrm{~L}$ $\min ^{-1}, 325{ }^{\circ} \mathrm{C}$, ionisation $130 \mathrm{~V}$, internal reference mass $121.050873 \mathrm{~m} / \mathrm{z}$ and $922.009798 \mathrm{~m} / \mathrm{z}$.

The acquired data had been processed using MassHunter 7.00 software, Agilent Technologies (Santa Clara, USA). The identification of separated compounds in extracted ion chromatograms was based on the $[\mathrm{M}+\mathrm{H}]+$ ion determination.

Chlorogenic acid, $\alpha$-solanine and $\alpha$-chaconine were identified based on used standards. The relative standard deviation was determined to be less than $2.0 \%$. Phenylalanine was identified based on the retention time and mass-to-charge ratio, acquired from the literature (Lopez-Cobo et al., 2014).

Statistical analysis

Results are presented as mean values on a dry weight (dw) of peels. The compound degradation data approximation was conducted in the MS Office Excel 2015 from Microsoft (Redmond, USA). Correlation coefficients for calibration curves were calculated using MS Office Excel 2015 (p<0.001). The statistical analysis of the half-life values of the identified compounds had been conducted using the one-way analysis of variance (ANOVA, $\mathrm{p} \leq 0.05$ ).

\section{Results and Discussion}

Graphs of $\alpha$-chaconine and $\alpha$-solanine degradation dynamics can be seen in Figure 1.

Friedman et al. (2017) conducted a research on potato peels from several conventional and organic plant varieties and showed that $\alpha$-chaconine levels could vary for conventional potato varieties for 424 to $1,297 \mathrm{mg} \mathrm{kg}^{-}$ 1 and 610 to $2,830 \mathrm{mg} \mathrm{kg}^{-1}$ for organic varieties. For $\alpha$-solanine, in the same study, values varied from 215 to $412 \mathrm{mg} \mathrm{kg}^{-1}$ and from 239 to $750 \mathrm{mg} \mathrm{kg}^{-1}$ respectively. In the present study, $\alpha$-solanine levels for all three peel 
types before storage were ca. $360 \mathrm{mg} \mathrm{kg}^{-1}$, and all of them showed similar degradation profiles.
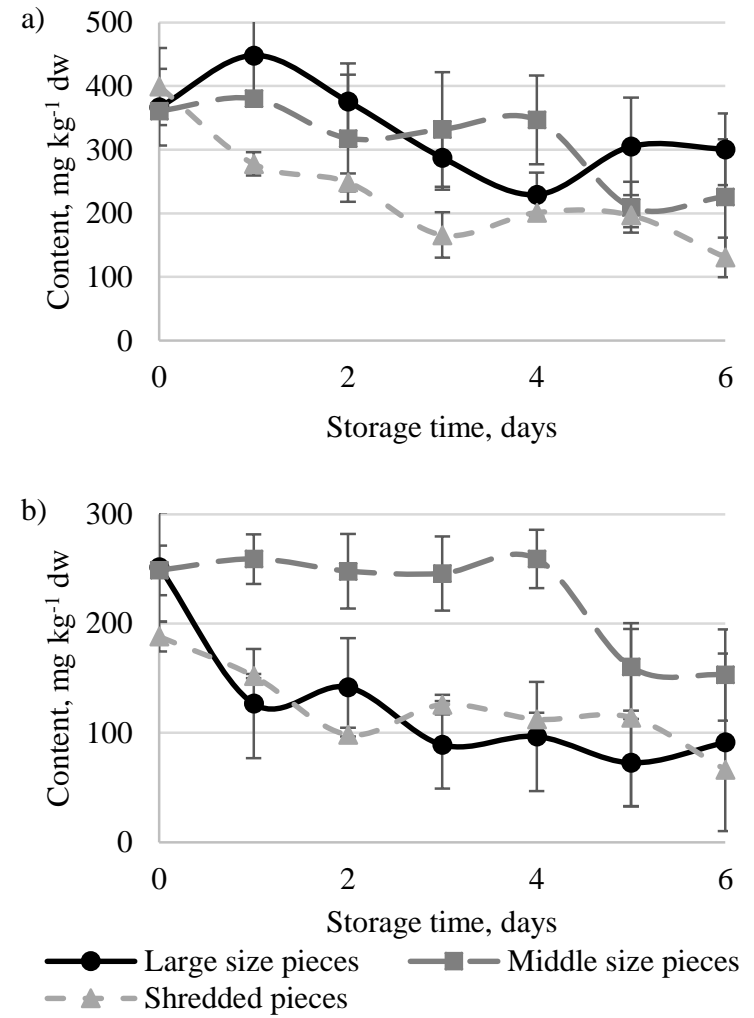

Figure 1. The decline of $\alpha$-solanine (a) and $\alpha$ chaconine (b) in potato peel wastes during the storage under ambient conditions

The linear approximation of acquired data showed that $\alpha$-solanine degradation rates were higher in the peel of smaller size. Middle size peel samples showed similar results, but with a bigger rate. The fastest $\alpha$-solanine degradation rates were observed in shredded peel samples. $\alpha$-solanine degradation in three types of soil had been reported to have a half-life period of 1.8 to 4.1 days at $15^{\circ} \mathrm{C}$. $\alpha$-solanine degradation in the soil had been reported previously, and it appeared to be related to the presence of different sorbents in low amounts (Jensen et al., 2009). In the present study, biologically active compounds in a greater content were exposed to the environmental impacts and enzymatic activity due to the cell disruption in peels (the bigger was the shredding rate - the bigger exposure). As a result, identified compounds showed lower degradation rates in samples with a higher rate of unbroken cells. For $\alpha$-chaconine, large and shredded peel samples showed similar degradation rates except on the first day, making a similar declining picture. In the case of middle-size peel samples, $\alpha$-chaconine levels were mostly constant during the first four days of storage, with an intensive recession on a subsequent day. Several explanations are possible. First of all, glycoalkaloids are distributed unevenly in the potato peel, as exposure to the light (including fluorescent) rapidly stimulates their production (Rocha et al., 2015; Romanucci et al., 2016). As a result of sample storage in the ambient conditions without being sheltered from the light beams (being sheltered from the direct sunlight, there is still a possibility of reflected light beam reaching samples), additional glycoalkaloid formation could occur during the storage. This fact addresses the increase in $\alpha$ solanine content after the second day of storage. These results mean that potato peel wastes (by-products) should be stored while protected from the direct and reflected light.

Table 1 is showing half-life periods of four identified compounds.

Table 1

The half-life of the identified biologically active compounds based on a linear data approximation, in days

\begin{tabular}{lcccc}
\hline $\begin{array}{l}\text { Identified } \\
\text { compound }\end{array}$ & Value & LSP & MSP & SP \\
\hline$\alpha$-solanine & Ac. & n.a. & n.a. & $2.5^{\mathrm{a}}$ \\
& Ca. & 9.5 & 8.1 & $3.9^{\mathrm{b}}$ \\
& $\mathrm{R}^{2}$ & 0.46 & 0.69 & 0.78 \\
$\alpha$-chaconine & Ac. & $1.1^{\mathrm{a}}$ & n.a. & $5.5^{\mathrm{a}}$ \\
& $\mathrm{Ca}$. & $2.9^{\mathrm{b}}$ & 8.9 & $4.9^{\mathrm{b}}$ \\
& $\mathrm{R}^{2}$ & 0.64 & 0.61 & 0.72 \\
Chlorogenic & $\mathrm{Ac}$. & $2.5^{\mathrm{a}}$ & $1.9^{\mathrm{a}}$ & n.a. \\
acid & $\mathrm{Ca}$. & $2.7^{\mathrm{a}}$ & $2.4^{\mathrm{b}}$ & n.a. \\
& $\mathrm{R}^{2}$ & 0.81 & 0.91 & n.a. \\
Phenylalanine & Ac. & $3.4^{\mathrm{a}}$ & $1.1^{\mathrm{a}}$ & $1.3^{\mathrm{a}}$ \\
& $\mathrm{Ca}$. & $3.5^{\mathrm{a}}$ & $3.1^{\mathrm{b}}$ & $2.8^{\mathrm{b}}$ \\
& $\mathrm{R}^{2}$ & 0.75 & 0.60 & 0.81 \\
\hline
\end{tabular}

* Lowercase letters indicate the difference between actual and calculated half-life values for each compound and peel type. LSP - large size peel, MSP - middle size peel, SP - shredded peel, Ac. - actual half-life, Ca. - calculated half-life, $\mathrm{R}^{2}$ - coefficient of determination of calculated values, n.a. - not applicable.

Higher glycoalkaloid content can be preferred for the pharmaceutical industry as recent studies show that, despite their high toxicity, glycoalkaloids can exhibit health-promoting effects, including the ability to lower blood cholesterol (Friedman et al., 2000) and even exhibit anti-cancer activity (Friedman et al., 2007). Regarding the current study, glycoalkaloid degradation rates did not play a significant role, because (how it will be stated further) overall results showed that it is not advisable to store large and middle size peel pieces for longer than two days, while shredded peels are not applicable for proposed processing purposes. The degradation of $\alpha$-solanine and $\alpha$-chaconine during this time had been minimal, except $\alpha$-chaconine that showed a decline in large peel pieces (Figure 1). Existing guidelines limit the glycoalkaloid content in food products to $200 \mathrm{mg} \mathrm{kg}^{-1}$ on fresh weight. It was shown that these limits may be too high (Friedman et al., 2007), as a clinical study on human volunteers resulted in the gastrointestinal disturbance of one participant after the consumption of food with a permitted glycoalkaloid content (Mensinga et al., 2005). Additionally, it was reported that the actual frequency of glycoalkaloid poisoning is unknown, as many poisoning incidences of may be underreported, because following symptoms include vomiting that more likely accepted as a result of 
ingesting foodborne pathogens, general viral infections, or gastrointestinal illness (Jaspreet, Lovedeep, 2009). In case of the present study, consumption even of pure potato peel samples should not cause a toxic reaction, as recalculation on fresh peel weight will decrease average glycoalkaloid concentration in the samples till ca. $90 \mathrm{mg}$ $\mathrm{kg}^{-1}$. In case of application of the produced extract in food production, it will be very important to make sure not to exceed safety limits.

Figure 2 is showing the dynamics of chlorogenic acid concentration. It can be seen that middle and large size peels exhibit similar tendencies. At the same time, chlorogenic acid degraded almost fully in shredded samples already during the peeling process. It can be a result of the cell structure disruption, and the straight contact of plant metabolites and enzymes, that can undergo several possible reaction pathways that had been discussed previously in detail by another authors (Fifen et al., 2011; Galano et al., 2016; Tošović et al., 2017).

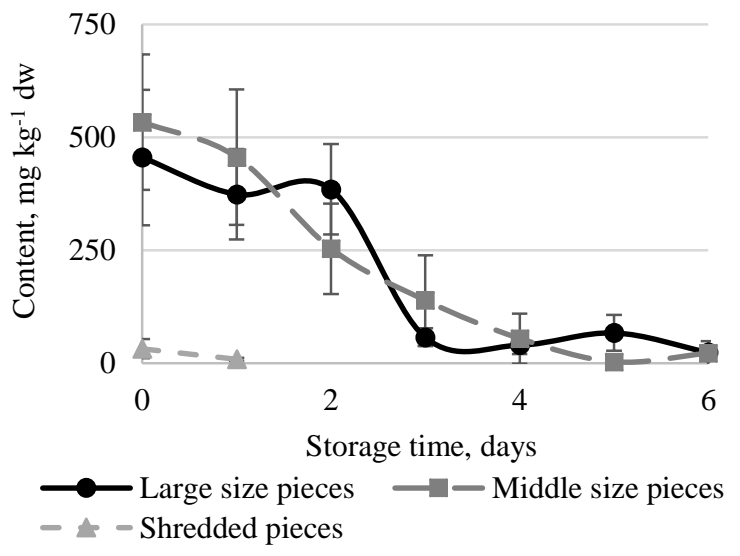

Figure 2. The decline of chlorogenic acid degradation in potato peel wastes during the storage under ambient conditions

Additionally, the samples did not undergo any additional treatment in order to deactivate polyphenol oxidase, a major cause of the enzymatic browning. As an additional plant protection mechanism, polyphenol oxidase catalyses monophenols transformation to $o$-diphenols and further $o$ dihydroxyphenols to $o$-quinones, with further polymerisation. In addition, reaction with amino acid groups of cellular proteins are taking place, that is a reason for brown and/or black pigment formation (Thygesen et al., 1995). In combination with exposed cell components, these processes significantly increase reaction speed and decrease chlorogenic acid content. As a result, in general, it is not reasonable to process shredded peel for phenolic compound extraction. Alternatively, large and medium-sized peel by-products could be used for this purpose during the first two days of storage at ambient conditions, showing half-life time of $2.7\left(\mathrm{R}^{2}=0.81\right)$ and $2.4\left(\mathrm{R}^{2}=0.91\right)$ days, respectively. In addition, it was possible to identify one of the essential amino acids, phenylalanine, based on the massto-charge ratio, acquired from the literature.
Degradation graphs are presented in Figure 3. Taking in consideration time when compound concentration decreased in half, phenylalanine had faster degradation rate in comparison with glycoalkaloids, with a half-life period of 3.5 days for large, 3.1 days for middle size peel, and 2.8 days for shredded peel samples. But starting with the second day of storage, phenylalanine concentration becomes almost constant.

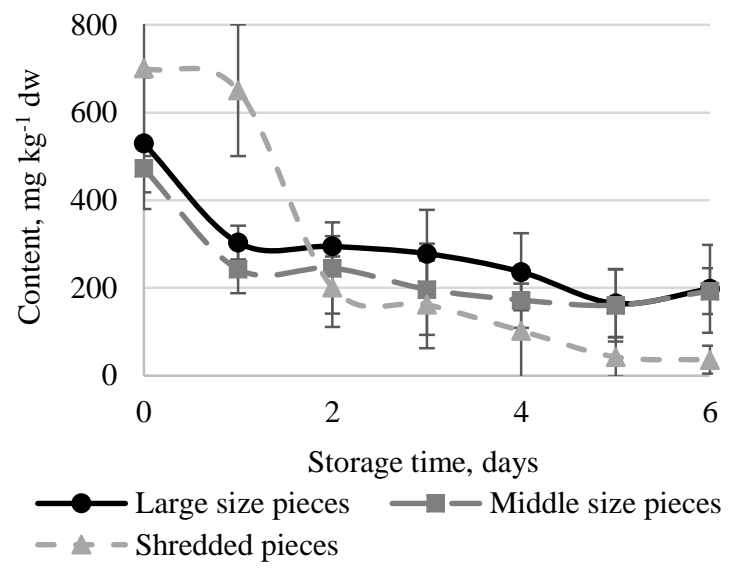

Figure 3. The decline of phenylalanine in potato peel wastes during the storage under ambient conditions

Phenylalanine, after the forming of p-coumaroylcoenzyme A (p-coumaroyl-CoA), is known to take a part in the chlorogenic acid synthesis through 'core phenylpropanoid pathway’ (Valiñas et al., 2017).

Comparing Figures 2 and 3, it can be seen that samples containing whole cells (large- and middle-sized peels) exhibit slower chlorogenic acid degradation rates during first days of storage, but a followed rapid decrease on a third day. During the same timeframe, phenylalanine degradation had been most active, but linear for the remaining storage time. Unfortunately, it was not possible to determine a wide range of metabolites that were present in extracts. As a result, it only can be assumed that chlorogenic acid synthesis could still occur during this first days, while later some of the reaction components could run out or become inactive, triggering the end of chlorogenic acid synthesis. The opposite situation can be seen in the case of shredded peel samples (as chlorogenic acid had been practically absent), where phenylalanine had been stable for the first several days, showing a rapid decrease only on a third. This could be a result of microbial activity, as the unpleasant smell shortly followed. At the same time, in addition to the chlorogenic acid pathway, the p-coumaroyl-CoA can take a core anthocyanin pathway, forming flavan-3-ols: catechin and epicatechin (Valiñas et al., 2017). As a result, taking in consideration also parallel degradation processes, rapid phenylalanine consumption does not result in the spikes in the chlorogenic acid content (synthesis). Unfortunately, there is not enough available published information to make definitive conclusions about exactly what type of processes are taking place in peels 
that are separated from the potato tuber during the abrasion peeling process.

After the storage time, the surface of large and middle size peel pieces had been visually dry, but shredded peel represented a homogeneous mass with a pronounced microbiological decomposition signs. This can be a result of differences in cell integrities, that influenced the moisture evaporation and biologically active compound (including those with antimicrobial properties) degradation as had been discussed previously.

\section{Conclusions}

$\alpha$-solanine and $\alpha$-chaconine were the most stable among the analysed biologically active compounds in the present study. Chlorogenic acid concentration showed slower decrease rates in the large and middle size peel pieces during the first days of storage, when compared to small size samples; possibly due to ongoing chlorogenic acid synthesis from phenylalanine. For biologically active compound extraction from industrial potato peel wastes, it is recommended to use only potato peels that still contain whole cells, and their storage should not exceed two days at ambient conditions. Deeper studies on the biologically active compound degradation dynamics are necessary to maximise the yield of extractable target compounds from the industrial potato processing wastes.

\section{Acknowledgement}

The present study was partially supported by the Project No. 4 'Sustainable use of local agricultural resources for qualitative and healthy food product development (FOOD)' of the Latvian State Research program 'Agricultural Resources for Sustainable Production of Qualitative and Healthy Foods in Latvia' (AgroBioRes) (2014-2017). Research material was kindly donated by the Institute of Agricultural Resources and Economics, Latvia.

\section{References}

1. Al-Weshahy A., Rao V.A. (2012) Potato peel as a source of important phytochemical antioxidant nutraceuticals and their role in human health-A Review. In: Phytochemicals as Nutraceuticals - Global Approaches to Their Role in Nutrition and Health. V. Rao (ed). Shanghai: InTech, p. 207-224.

2. Amado I.R., Franco D., Sanchez M., Zapata C., Vazquez J.A. (2014) Optimisation of antioxidant extraction from Solanum tuberosum potato peel waste by surface response methodology. Food Chemistry, Vol. 165, p. 290-299.

3. Cardoso L.C., Serrano C.M., Quintero E.T., Lopez C.P., Antezana R.M., de la Ossa, E.J.M. (2013) High pressure extraction of antioxidants form Solanum stenotomun peel. Molecules, Vol 18, p. 3137-3151.

4. Fifen J.J., Nsangou M., Dhaouadi Z., Motapon O., Jaidane N. (2011) Solvent effects on the antioxidant activity of 3,4-dihydroxyphenylpyruvic acid: DFT and TD-DFT studies. Computational and Theoretical Chemistry, Vol. 966(1-3), p. 232-243.

5. Friedman M. (1997) Chemistry, biochemistry, and dietary role of potato polyphenols. A Review. Journal of Agricultural and Food Chemistry, Vol. 45(5), p. 1523-1540.

6. Friedman M. (2004) Analysis of biologically active compounds in potatoes (Solanum tuberosum), tomatoes (Lycopersicon esculentum), and jimson weed (Datura stramonium) seeds. Journal of Chromatography A, Vol. 1054, p. 143-155.

7. Friedman M., Fitch T.E., LevinN C.E., Yokoyama W.H. (2000) Feeding tomatoes to hamsters reduces their plasma low-density lipoprotein cholesterol and triglycerides. Journal of Food Science, Vol. 65(5), p. 897-900.

8. Friedman M., Kozukue N., Kim H.J.J., Choi S.H.H., Mizuno M. (2017) Glycoalkaloid, phenolic, and flavonoid content and antioxidative activities of conventional nonorganic and organic potato peel powders from commercial gold, red, and Russet potatoes. Journal of Food Composition and Analysis, Vol. 62(March), p. 69-75.

9. Friedman M., McQuistan T., Hendricks J.D., Pereira C., Bailey G. S. (2007) Protective effect of dietary tomatine against dibenzo[a,1]pyrene (DBP)-induced liver and stomach tumors in rainbow trout. Molecular Nutrition \& Food Research, Vol. 51(12), p. 1485-1491.

10. Galano A., Mazzone G., Alvarez-Diduk R., Marino T., Alvarez-Idaboy J.R., Russo N. (2016) Food antioxidants: chemical insights at the molecular level. Annual Review of Food Science and Technology, Vol. 7(1), p. 335-352.

11. Göksungur Y., Uzunoullari P., Dağbağli S. (2011) Optimization of pullulan production from hydrolysed potato starch waste by response surface methodology. Carbohydrate Polymers, Vol. 83, p. 1330-1337.

12. Hossain M.B., Tiwari B.K, Gangopadhyay N., O’Donnell C.P., Brunton N.P., Rai D.K. (2014) Ultrasonic extraction of steroidal alkaloid from potato peel waste. Ultrasonic Sonochemistry, Vol 21, p. 1470-1476.

13. Hsieh Y.L., Yeh Y.H., Lee Y.T., Huang C.Y. (2016) Dietary potato peel extract reduces the toxicity of cholesterol oxidation products in rats. Journal of Functional Foods, Vol. 27, p. 461-471.

14. Im H.W., Suh B.S., Lee S.U., Kozukue N., OhnisiKameyama M., Levin C. E., Friedman M. (2008) Analysis of phenolic compounds by high-performance liquid chromatography and liquid chromatography/mass spectrometry in potato plant flowers, leaves, stems, and tubers and in home-processed potatoes. Journal of Agricultural and Food Chemistry, Vol. 56(9), p. 3341-3349.

15. Jaspreet S., Lovedeep K. (2009) Advances in Potato Chemistry and Technology. Academic Press. 528 p.

16. Jensen P.H., Pedersen R.B., Svensmark B., Strobel B.W., Jacobsen O.S., Hansen H.C.B. (2009) Degradation of the potato glycoalkaloid $\alpha$-solanine in three agricultural soils. Chemosphere, Vol. 76(8), p. 1150-1155.

17. Habeebullah K.S.F., Nielsen N.S., Jacobsen C. (2010) Antioxidant activity of potato peel extracts in a fishrapeseed oil mixture and in oil-in-water emulsions. Journal of the American Oil Chemists' Society, Vol. 87(11), p. 1319-1332.

18. Liang S., McDonald A.G. (2014) Chemical and thermal characterization of potato peel waste and its fermentation residue as potential resources for biofuel and bioproducts production. Journal of Agricultural and Food Chemistry, Vol. 62(33), p. 8421-8429.

19. Liang S., McDonald A.G. (2015) Anaerobic digestion of pre-fermented potato peel wastes for methane production. Waste Management, Vol. 46, p. 197-200. 
20. Liang S., McDonald A.G., Coats E.R. (2014) Lactic acid production with undefined mixed culture fermentation of potato peel waste. Waste Management, Vol. 34(11), p. 2022-2027.

21. Lopez-Cobo A., Gomez-Caravaca A.M., Cerretani L., Segura-Carretero A., Fernandez-Gutierrez A. (2014) Distribution of phenolic compounds and other polar compounds in the tuber of Solanum tuberosum L. by HPLC-DAD-q-TOF and study of their antioxidant activity. Journal of Food Composition and Analysis, Vol. 36(1-2), p. 1-11.

22. Luthria D.L. (2012) Optimization of extraction of phenolic acids form a vegetable waste product using a pressurized liquid extraction. Journal of Functional Foods, Vol. 4, p. 842-850.

23. Mäder J., Rawel H., Kroh L.W. (2009) Composition of phenolic compounds and glycoalkaloids alpha-solanine and alpha-chaconine during commercial potato processing. Journal of Agricultural and Food Chemistry, Vol. 57(14), p. 6292-6297.

24. Mane S., Bremner D.H., Tziboula-Clarke A., Lemos M.A. (2015) Effect of ultrasound on the extraction of total anthocyanins from Purple Majesty potato. Ultrasonics Sonochemistry, Vol. 27, p. 509-514.

25. Mansour E.H., Khalil A.H. (2000) Evaluation of antioxidant activity of some plant extracts and their application to ground beef patties. Food Chemistry, Vol. 69(2), p. 135-141.

26. Matharu A.S., de Melo E.M., Houghton J.A. (2016) Opportunity for high value-added chemicals from food supply chain wastes. Bioresource Technology, Vol. 215, p. $123-130$.

27. Mensinga T.T., Sips A.J.A.M., Rompelberg C.J.M., van Twillert K., Meulenbelt J., van den Top H.J., van Egmond H.P. (2005) Potato glycoalkaloids and adverse effects in humans: an ascending dose study. Regulatory Toxicology and Pharmacology, Vol. 41(1), p. 66-72.

28. Navarre D.A., Pillai S.S., Shakya R., Holden M.J. (2011) HPLC profiling of phenolics in diverse potato genotypes. Food Chemistry, Vol. 127(1), p. 34-41.

29. Rayburn J.R., Bantle J.A., Friedman M. (1994) Role of carbohydrate side chains of potato glycoalkaloids in developmental toxicity. Journal of Agricultural and Food Chemistry, Vol. 42(7), p. 1511-1515.
30. Rocha A.B.O., Honório S.L., Messias C.L., Otón M., Gómez P.A. (2015) Effect of UV-C radiation and fluorescent light to control postharvest soft rot in potato seed tubers. Scientia Horticulturae, Vol. 181, p. 174-181.

31. Romanucci V., Pisanti A., Di Fabio G., Davinelli S., Scapagnini G., Guaragna A., Zarrelli A. (2016) Toxin levels in different variety of potatoes: Alarming contents of $\alpha$-chaconine. Phytochemistry Letters, Vol. 16, p. 103-107.

32. Sabeena Farvin K.H., Grejsen H.D., Jacobsen C., Farvin S.K.H., Grejsen H.D., Jacobsen C. (2012) Potato peel extract as a natural antioxidant in chilled storage of minced horse mackerel (Trachurus trachurus): Effect on lipid and protein oxidation. Food Chemistry, Vol. 131(3), p. 843-851.

33. Samarin A.M., Poorazarang H., Hematyar N., Elhamirad A. (2012) Phenolics in potato peels: extraction and utilization as natural antioxidants. World Applied Science Journal, Vol. 18(2), p. 191-195.

34. Schieber A., Saldaña M. (2009) Potato peels : A source of nutritionally and pharmacologically interesting compounds - A Review. Food, Vol. 3(2), p. 23-29.

35. Singh N., Rajini P.S. (2008) Antioxidant-mediated protective effect of potato peel extract in erythrocytes against oxidative damage. Chemico-Biological Interactions, Vol. 173(2), p. 97-104.

36. Thygesen P., Dry I., Robinson S. (1995) Polyphenol oxidase in potatoe. Plant Physiology, Vol. 109, p. 525-531.

37. Tošović J., Marković S., Dimitrić Marković J.M., Mojović M., Milenković D. (2017) Antioxidative mechanisms in chlorogenic acid. Food Chemistry, Vol. 237, p. 390-398.

38. Valiñas M.A., Lanteri M.L., ten Have A., Andreu A.B. (2017) Chlorogenic acid, anthocyanin and flavan-3-ol biosynthesis in flesh and skin of Andean potato tubers (Solanum tuberosum subsp. andigena). Food Chemistry, Vol. 229, p. 837-846.

39. Wijngaard H.H., Ballay M., Brunton N. (2012) The optimisation of extraction of antioxdants form potato peel by pressurised liquids. Food Chemistry, Vol. 133, p. $1123-1130$

40. Williams C.A., Grayer R.J. (2004) Anthocyanins and other flavonoids. Natural Product Reports, Vol. 21(4), p. 539-573. 